\title{
A method for improved identification of postcrania from mammalian fossil assemblages: multivariate discriminant function analysis of camelid astragali
}

\author{
Edward Byrd Davis and Brianna K. McHorse
}

\begin{abstract}
Character-rich craniodental specimens are often the best material for identifying mammalian fossils to the genus or species level, but what can be done with the many assemblages that consist primarily of dissociated postcrania? In localities lacking typically diagnostic remains, accurate identification of postcranial material can improve measures of mammalian diversity for wider-scale studies. Astragali, in particular, are often well-preserved and have been shown to have diagnostic utility in artiodactyls. The Thousand Creek fauna of Nevada ( $\sim \mathrm{Ma}$ ) represents one such assemblage rich in postcranial material but with unknown diversity of many taxa, including camelids. We use discriminant function analysis (DFA) of eight linear measurements on the astragali of contemporaneous camelids with known taxonomic affinity to produce a training set that can then be used to assign taxa to the Thousand Creek camelid material. The discriminant function identifies, at minimum, four classes of camels: "Hemiauchenia", Alforjas, Procamelus, and ?Megatylopus. Adding more specimens to the training set may improve certainty and accuracy for future work, including identification of camelids in other faunas of similar age. For best statistical practice and ease of future use, we recommend using DFA rather than qualitative analyses of biplots to separate and diagnose taxa.
\end{abstract}

Edward Byrd Davis. University of Oregon Museum of Natural and Cultural History and Department of Geological Sciences, 1680 East 15th Avenue, Eugene, Oregon 97403. edavis@uoregon.edu Brianna K. McHorse. University of Oregon Clark Honors College and Department of Biology, 1293 University of Oregon, Eugene, Oregon 97403. Current address: Harvard University Department of Organismic and Evolutionary Biology, 26 Oxford Street, Cambridge, Massachusetts 02138. bmchorse@fas.harvard.edu

KEY WORDS: discriminant function analysis; Camelidae; Thousand Creek; astragalus; Miocene; Hemphillian 


\section{INTRODUCTION}

The camelid remains of the Thousand Creek local fauna of Nevada ( 8 Ma; Merriam, 1910; Prothero and Davis, 2008) present an interesting systematic and taxonomic problem. The faunal assemblage has accumulated in such a way that there is a dearth of cranial and dental material preserved relative to the extensive number of postcranial (especially podial) elements. As with most fossil vertebrate systematics, fossil camel species are typically diagnosed through characters of their cranial and dental remains. Skulls and teeth have always been considered the best elements for identifying mammal fossils, as they contain a large number of diagnostic characters. In this way, the coordinated suites of characters (preferably apomorphies; Bell et al., 2010) that vertebrate paleontologists use to diagnose fossils are readily available for study. Disassociated postcranial remains are usually diagnosed based on a comparison of frequency and size with the cranial and dental elements from an assemblage. This leaves vertebrate paleontologists at a loss when considering assemblages consisting primarily of dissociated postcranial elements. A growing body of literature suggests, however, that postcrania can provide valuable taxonomic information (e.g., Klein et al., 2010; Louys et al., 2012). Spaulding and Flynn (2012) recently included postcranial characters in a Carnivoramorpha phylogeny, allowing them to clarify the phylogenetic context of previously ignored taxa known mostly from postcrania. The specimens included by Spaulding and Flynn (2012) were already identified, allowing them to use a phylogenetic approach; in contrast, our work seeks to identify postcrania using a comparative statistical approach.

The Thousand Creek fauna is heavily biased towards the preservation of postcranial elements. For example, the collections of the University of California Museum of Paleontology contain 14 cranial or dental specimens from camelid taxa, none of which are diagnostic, and 149 podial elements alone. Metapodial elements, phalanges, and limb bones represent further abundant postcranial material. Rhinocerotids show a similar distribution ( 5 cranial/dental, 67 podial), as do antilocaprids $(46,145)$. The Thousand Creek assemblage has characteristics of a lake-shore environment as suggested by sedimentology and tectonic setting, as well as carnivore activity (Wendell, 1970; Ach and Swisher, 1990; Behrensmeyer et al., 1992; Davis and Pyenson, 2007). Equids do not follow the same pattern ( $21 \mathrm{cranial} / \mathrm{dental}, 26$ podial), possi- bly reflecting a different taphonomic pathway or other preservational bias that merits future study.

A paleontological sample as large as the Thousand Creek camelid fauna should not be ignored simply because the assemblage lacks character-rich elements. In fact, the postcrania of camelids can be diagnostic of taxa in the absence of cranial material. Breyer (1983) demonstrated the diagnostic utility of camelid metapodials using a combination of qualitative and quantitative characters. DeGusta and Vrba (2003) examined ecomorphological diversity in extant African bovid astragali, testing a new method of paleoenvironmental reconstruction. They used discriminant function analysis (DFA) to create a function that predicts the preferred environment of an animal based on its astragalar morphology. The Martinez and Sudre (1995) examination of Paleocene artiodactyl astragali demonstrated conclusively that astragalar size is tied directly to body size, leading to the identification of two separate species at one site based on mass estimates. Davis and Calède (2012) demonstrated additionally that the DeGusta and Vrba (2003) astragalus dataset contains enough taxonomic information to potentially diagnose genera of African antelope. Consequently, multivariate analysis of camel astragali should reveal body-size partitioning in the Thousand Creek taxa if it exists, as it does among many modern coexisting artiodactyls (McNaughton and Georgiadis, 1986), and may provide enough information for generic diagnosis. Similar methods of measuring the astragali of antilocaprids from Thousand Creek have demonstrated that the two known species of antelope do not show extensive body-size partitioning, differing little enough in size that individual astragali from the middle of the size range are not assignable to one species (Davis and Calède, 2012). This existing body of research demonstrating the functional utility of astragali and the linear measurements (Figure 1) introduced by DeGusta and Vrba $(2003,2005)$ makes astragali a logical first choice for investigating the problem of unidentified camel postcrania. Our investigation of astragali is the first step in a larger program that we are actively extending to include metapodials, following Breyer (1983), phalanges, following DeGusta and Vrba (2005), and other postcranial elements.

Astragali have become important in studies of mammalian postcrania because of their small size, high durability, and extensive homologous condylar surfaces. These attributes are interlinked, as the key position the astragalus holds in the ankle-joint 

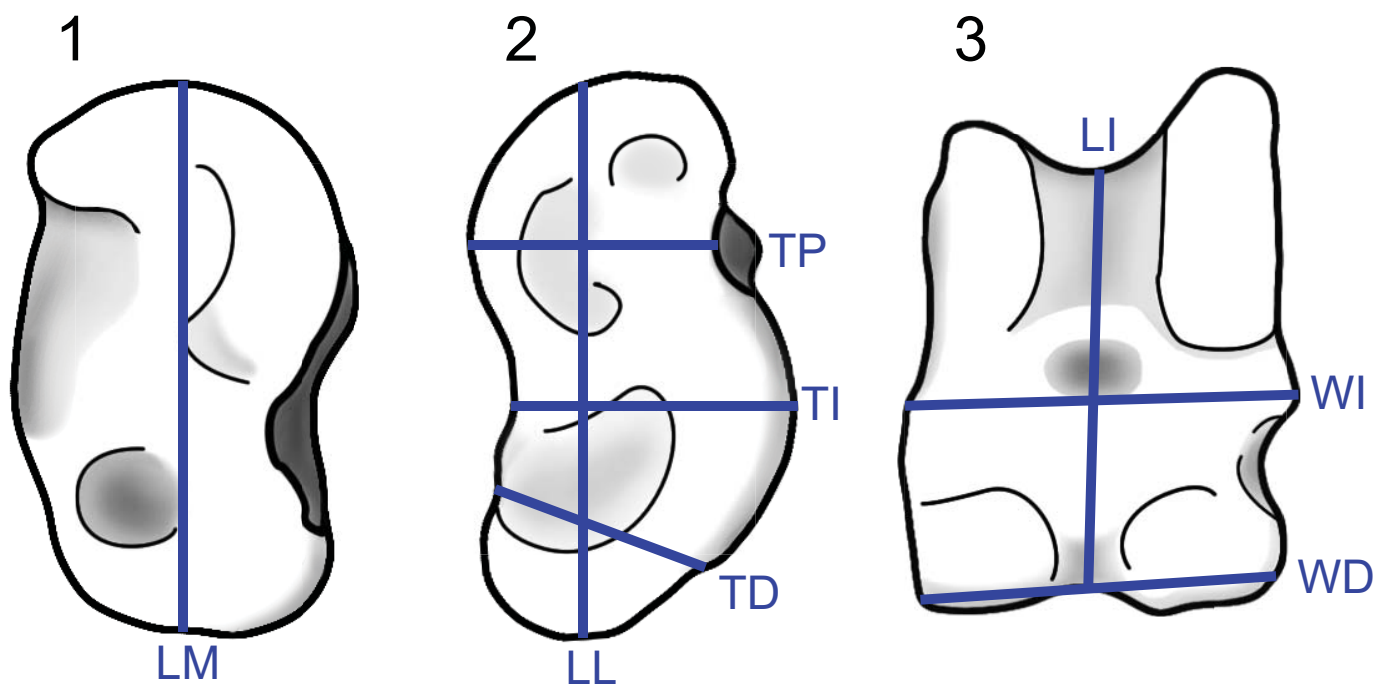

FIGURE 1. Illustration of astragali showing the dimensions used in this study. After DeGusta and Vrba (2003). 1.1, medial view; 1.2, lateral view; 1.3, anterior view. Abbreviations: $L M=$ medial length; $L I=$ intermediate length; $L L=$ lateral length; TD= distal thickness; $\mathrm{TI}=$ intermediate thickness; $\mathrm{TP}=$ proximal thickness; $\mathrm{WD}=$ distal width; $\mathrm{WI}=$ intermediate width.

creates both the condylar surfaces and the high durability of the bone. In fossil mammal assemblages dominated by postcrania, like the one from Thousand Creek, the durability of astragali makes them a common element. Condylar homologies make biometric comparisons possible, as workers can be sure that they measure comparable dimensions on different specimens. The anatomy of artiodactyl astragali also makes more detailed comparisons possible, because the two articulations of the distal trochlea (which are unique to artiodactyls and evolved once in the history of the clade; Schaeffer, 1947; Martinez and Sudre, 1995) provide additional landmarks for biometric comparisons relative to the single trochlea of other taxa.

If astragalar morphology (Figure 1) can successfully distinguish between camelid taxa, then morphometric analysis of the Thousand Creek material and comparison to samples of known composition from other contemporaneous sites should allow us to identify the taxa that were present in the Thousand Creek area eight million years ago. We hypothesize:

1. Astragalar variation amongst the six known genera of camels from the early Hemphillian will include taxonomically informative differences in both size and shape.

2. Astragalar morphology can distinguish amongst these genera.

3. The astragali from Thousand Creek will fall within the expected range of some or all of these six known genera.

To test these hypotheses we first use a Principal Components Analysis (PCA) to qualitatively test Hypothesis 1, examining whether camelid astragali of known taxonomic affinity from the early Hemphillian show distinct size and/or shape partitioning. PCA is a typical exploratory tool for visualizing multivariate data in a lower-dimensional space, allowing straightforward qualitative analysis of patterns (Hammer and Harper, 2006). After the qualitative assessment, we will test Hypothesis 2 by constructing a discriminant function based on the known astragali. Discriminant functions have proven useful in distinguishing amongst groups of vertebrate fossils given adequate multivariate information (DeGusta and Vrba 2003, 2005; Hopkins and Davis, 2009; and van Asperen, 2011). If this discriminant function can accurately distinguish identity of these specimens from sites of similar age to Thousand Creek, then we will be able to test Hypothesis 3 and potentially identify the unknown Thousand Creek camelids.

\section{MATERIALS AND METHODS}

\section{Materials}

The six known genera of camels from the period $\sim 8 \mathrm{Ma}$ (early Hemphillian) in North America are Aepycamelus, Megatylopus, Procamelus, Alforjas, Hemiauchenia, and Pleiolama, a relatively 
TABLE 1. Summary of specimens used in the training set. F:AMNH refers to the Frick collections of the AMNH; UCMP is the University of California Museum of Paleontology collections. "Hemiauchenia" minima and $H$. edensis were reassigned by Webb et al. (2008) from Procamelus (Frick, 1921). "H." minima was suggested to be different enough from $H$. vera that it should have its own generic identification (Webb et al., 1981). Pleiolama vera was reassigned from Hemiauchenia by Webb and Meachen (2004).

\begin{tabular}{llcc}
\hline \multicolumn{1}{c}{ Taxon } & \multicolumn{1}{c}{ Location } & Collection & $\mathbf{n}$ \\
\hline Aepycamelus & Mixon's Bone Bed, Levy Co., FL & F:AMNH & 48 \\
Megatylopus & Guymon, Texas Co., OK & F:AMNH & 23 \\
Procamelus & Blackhawk Ranch, Contra Costa Co., CA & UCMP & 6 \\
Alforjas & Guymon, Texas Co., OK & F:AMNH & 24 \\
"Hemiauchenia" minima & Mixon's Bone Bed, Levy Co., FL & F:AMNH & 66 \\
Hemiauchenia edensis & Mt. Eden, Riverside Co., CA & UCMP & 5 \\
Pleiolama & Edison Quarry, Sherman Co., KS & F:AMNH & 9 \\
\hline
\end{tabular}

new genus (Honey et al., 1998; Webb and Meachen, 2004). To make taxonomic assignments, we have compared the sample of astragali from Thousand Creek to exemplar populations of these genera from other early Hemphillian North American sites. Sites were chosen on the basis of published identifications of diagnostic cranial material where large within-site taxonomic size differences make us confident in the assignments of even isolated astragali. It is possible that some of these training set astragali are incorrectly identified, but such mistakes should be rare and would only add noise to our analysis. We are confident that our assignment of Thousand Creek astragali to known genera is conservative relative to the hypotheses we test.

Our identified sample is summarized in Table 1 (full data in supplementary materials). These identified remains constitute the training set we use to test whether astragalar morphology can distinguish late Miocene camelids, thus forming the basis of our analysis of unassigned material from the UCMP collections of Thousand Creek, NV: 36 complete astragali, 16 right and 20 left. The age of the Thousand Creek sequence has been constrained by a combination of radiometric dates and magnetostratigraphy to between 8.3 and $7.05 \mathrm{Ma}$ (Swisher, 1992; Streck and Grunder, 1995; Perkins et al., 1998; Prothero and Davis, 2008). Unfortunately, stratigraphic work in the region (Fyock, 1963; Wendell, 1970; Green, 1984) has focused on extrusive igneous history and economic geology rather than paleontological resources, so the Thousand Creek fossil sites are not well-constrained in the local stratigraphy. In addition, most mammal fossils from Thousand Creek are collected as float and lack clear stratigraphic context.

\section{Methods}

All measurements were made by EBD to eliminate inter-operator error. He measured each astragalus according to DeGusta and Vrba (2003), using only complete specimens that fully preserve all eight dimensions (Figure 1). All specimens were measured with Mitutoyo Digimatic digital calipers to the nearest $0.01 \mathrm{~mm}$ and data were uploaded directly to MS Excel worksheets from the calipers. EBD's previously established intra-operator measurement error for artiodactyl astragali is minor, with a maximum error of $2.32 \mathrm{~mm}(13 \%)$ and an average error of $0.24 \mathrm{~mm}(1 \%)$ between two measurements in a re-measuring test (Davis and Calède, 2012). These errors were normally distributed and smaller than the differences critical to our analysis.

We used JMP Pro (version 9.0.0, SAS Institute) to conduct Principal Components Analysis (PCA) and DFA on the measurements of the known sample. PCA allows viewing of multivariate data in a smaller number of dimensions, summarizing the majority of the variance in a dataset into orthogonal vectors, the principal components (Hammer and Harper, 2006). By viewing the spread of our data in the PCA, we can test Hypothesis 1. We performed Tukey's HSD tests $(p=0.05)$ along the first three principal components to test for significant groupings in size independent of shape (Principal Component 1) and shape independent of size (PCs 2 and 3). A Multivariate Hotelling Pairwise Comparison would address multivariate differences among taxa, but our question here specifically focuses on differences along independent shape or size axes. We tested these methods on both log-transformed and untransformed datasets with no difference in the results, so we present only analyses of untransformed data. 
DFA works by creating a set of equations that distinguish amongst nominal groupings using multiple continuous variables. We applied the DFA to astragali of known taxonomic affinity as a training set and used the resulting linear discriminant equation to classify the unknown astragali from Thousand Creek. We built our discriminant function initially using all eight linear dimensions. Using the corrected Akaike Information Criterion $\mathrm{AlC}_{\mathrm{C}}$ (Hurvich and Tsai, 1989), we tested the efficiency of this full model against simpler models by stepwise subtraction of variables. We constructed our discriminant function and performed the stepwise variable subtraction in JMP Pro 9.0 (SAS Institute). In addition, we evaluated the effectiveness of our full model by performing a jackknife analysis in the MASS package in R (Venables and Ripley, 2002; R Core Team, 2012). Jackknifing the discriminant function re-runs the analysis with each known specimen held out in turn and produces a taxonomic identification for that specimen as if it were an unknown. Jackknife verification is a more effective measure of evaluating success of a DFA than the standard output of the full model (DeGusta and Vrba 2003; Kovarovic et al., 2011; McGuire, 2011; Meloro, 2011; Meloro et al., 2013). We have included our entire training dataset Appendix as well as the R code in our supplemental data (both available online) so that other workers may build their own discriminant functions using all or a subset of our data, or by adding new training specimens.

Only classifications with greater than $50 \%$ certainty were considered. We also rejected identifications with a Mahalanobis distance (the squared distance from a specimen to the centroid of its predicted group) greater than two standard deviations away from the species mean shape, as in McGuire (2011). This helps correct for the limitation that DFA cannot identify taxa outside the training set.

We performed the discriminant function analysis (testing the training set and predicting taxonomic identity of the Thousand Creek specimens) at three levels of specificity to optimize identification of the unknown astragali:

1: Species-level, with each species identified separately;

2: Genus-level, with the Hemiauchenia species combined;

3: A broader level, primarily divided by genus but combining the recently-split Pleiolama and Hemiauchenia genera.
We also split the discriminant functions by size, after Meloro (2011), which has been shown to increase accuracy in predictions. This approach did not improve the prediction results, however, and so is not included in the paper.

\section{RESULTS}

\section{Principal Components Analysis}

PCA of known astragali indicates differences are concentrated along the first principal component (PC1; Figure 2; Table 2). As clearly indicated by the strong positive loadings on all variables, PC1 represents the size variation in the sample. The other PCs should then indicate size-independent shape variation (Hammer and Harper, 2006). The array along PC1 shows significant differences between all groups except the species of Pleiolama and Hemiauchenia according to Tukey's HSD test (Table 3). Along PC2, the Tukey test shows two main groups: Alforjas falls within the first; "H." minima, Aepycamelus, and Pleiolama fall within the second; and H. edensis, Megatylopus, and Procamelus are within both shape groups (Table 3). PC3 shows no clear signal, with the Tukey test pulling three groups with extensive overlap: (Procamelus, Alforjas, H. edensis), (Alforjas, A. major, $H$. edensis, "H." minima, $P$. vera), and (A. major, $H$. edensis, "H." minima, Megatylopus, P. vera). PCs 4 -7 are not significant.

\section{Discriminant Function Analysis}

The DFA applied at the species level incorrectly identified $24(13.26 \%)$ of the known specimens (Table 4; Figure 3). The binomial probability of this success rate, given random assignment to species, is approximately $p=3^{\star} 10^{-105}$. Most misidentifications were made in the assignment of specimens of "Hemiauchenia" minima to $H$. edensis (nine of 66) or to Pleiolama vera (five of 66). Four of 48 Aepycamelus major specimens were incorrectly assigned to Megatylopus. All other misidentifications consisted of single specimens (Table 4). Jackknifing the training dataset produced a comparable result, with 27 (14.9\%) misidentified (Table 5). The species-level discriminant function assigned 27 specimens from Thousand Creek to Procamelus, "H." minor, $H$. edensis, $P$. vera, $A$. major, Megatylopus, and Alforjas (Table 6). Nine of 36 specimens could not be assigned to a taxon with greater than $50 \%$ certainty. Mahalanobis cutoffs at two SDs eliminate 17 (70.4\%) positive identifications, including two of three Alforjas, all $H$. edensis, all P. vera, and all Megatylopus (Table 6). 


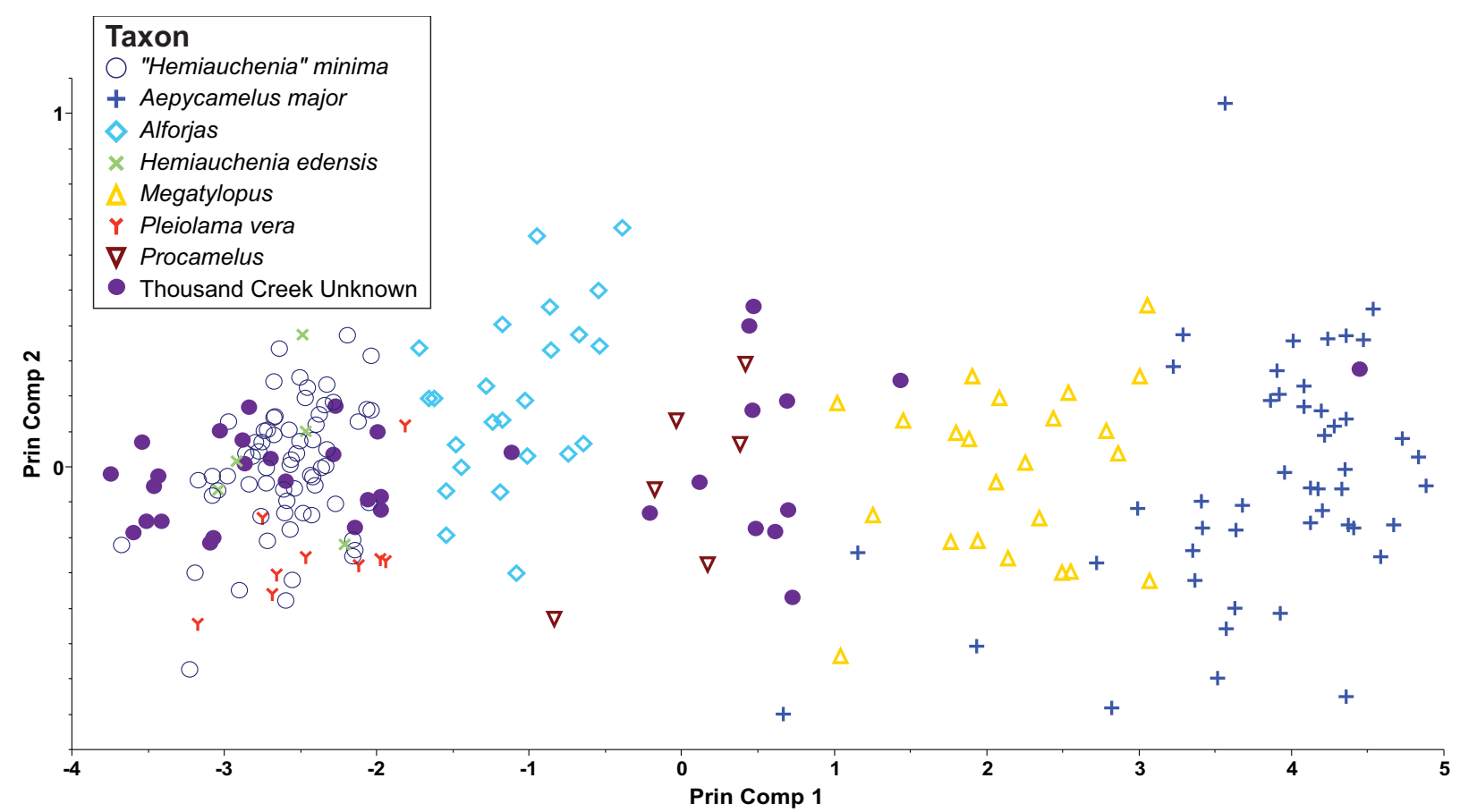

FIGURE 2. Principal Components of known astragali and Thousand Creek astragali illustrating the array of specimens along PC1, but no obvious differences along PC2. While a qualitative examination of PC2 produces no distinction, Tukey's HSD test indicates two separate groups (see Table 3). The Thousand Creek specimens show a single clear break in size, but without the DFA it would be impossible to quantify the certainty of group membership of specimens near the breaks between taxa.

The remaining identifications include Procamelus, "H." minima, and Alforjas.

Accuracy improves in the genus-level analysis, with only $16(8.84 \%$, binomial probability of $p=$ $\left.7 \star 10^{-108}\right)$ misclassifications in the training set (Table 4). The majority of misdentifications were in the assignment of Hemiauchenia to Pleiolama (seven of 71) and again four of 48 Aepycamelus assigned to Megatylopus. Jackknifing the training dataset produced a comparable result, with 18 (9.9\%) misidentified (Table 5). The discriminant function run on the Thousand Creek specimens identified the same six genera as the species-level analysis, with only one specimen that could not be identified with greater than $50 \%$ certainty (Table 6). Mahalanobis cutoffs at two SDs reject 25 (71.4\%) identifications, with remaining positive identifications of Alforjas, Hemiauchenia, and Procamelus.

Finally, combining Pleiolama with Hemiauchenia in the analysis leads to just six (3.32\%, binomial probability of $p=6 * 10^{-113}$ ) misclassifications in the training set (Table 4). The same four Aepycamelus specimens were misidentified to Megatylopus, and the remaining two misidentifications were in the assignment of Megatylopus to Aepycamelus and Alforjas to Hemiauchenia/Pleiolama. Jackknif- ing the training dataset produced a comparable result, with only 8 (4.4\%) misidentified (Table 5). This broadest discriminant function identifies all 36 complete Thousand Creek astragali with more than $50 \%$ certainty to the same set of genera as the previous two analyses: Procamelus, Hemiauchenia/ Pleiolama, Megatylopus, Aepycamelus, and Alforjas (Table 6). The Mahalanobis distance of 25 $(69.4 \%)$ of these identifications falls more than two SDs away from the group centroid, again leaving positive identifications of Alforjas, Hemiauchenial Pleiolama, and Procamelus.

\section{DISCUSSION}

The astragalar morphology of the known Hemphillian camels allows us to identify many of the camelids from Thousand Creek, producing relative abundances where before there were not even occurrence data. The application of discriminant function analyses to other elements in the assemblage (e.g., phalanges, metapodials, and calcanea) would provide additional lines of evidence about the relative abundances of the Thousand Creek taxa. Unlocking the potential of postcranial records in the Miocene will lead to a much larger dataset of abundances, enabling high- 
TABLE 2. Eigenvalues, percent of variance explained by each Principal Component, and eigenvectors for the PCA.

\begin{tabular}{ccccccccccc}
\hline PC & Eigenvalue & \% Var & LM & TD & TI & TP & LL & WD & WI & LI \\
\hline 1 & 7.8266 & 97.833 & 0.35543 & 0.34588 & 0.35451 & 0.35269 & 0.35615 & 0.35455 & 0.35353 & 0.35558 \\
2 & 0.074 & 0.925 & -0.1783 & 0.92393 & 0.00152 & -0.14375 & -0.13798 & -0.14678 & -0.078 & -0.21732 \\
3 & 0.0362 & 0.453 & 0.07511 & -0.00481 & 0.26301 & 0.66134 & 0.04432 & -0.41203 & -0.55816 & -0.06719 \\
4 & 0.0249 & 0.311 & -0.44952 & -0.08602 & 0.10998 & 0.49714 & -0.30148 & 0.12993 & 0.50994 & -0.40433 \\
5 & 0.0177 & 0.222 & 0.02768 & 0.1323 & -0.8413 & 0.40319 & 0.02876 & 0.28418 & -0.13635 & 0.10589 \\
6 & 0.012 & 0.149 & 0.27374 & 0.01073 & -0.2905 & 0.05553 & 0.19248 & -0.72612 & 0.52138 & -0.03666 \\
7 & 0.005 & 0.062 & 0.73846 & 0.00216 & 0.01329 & 0.00588 & -0.564 & 0.14335 & 0.00295 & -0.3403 \\
8 & 0.0036 & 0.045 & -0.11462 & 0.04095 & 0.02661 & 0.06888 & -0.63662 & -0.19375 & 0.0832 & 0.728 \\
\hline
\end{tabular}

powered analyses of paleoecological hypotheses across time and space. We have included all of our training data as well as our $\mathrm{R}$ code in the supplemental material to allow other workers to build upon our results.

Our discriminant function supports assignment of some UCMP Thousand Creek specimens to the genus level, but many specimens fall too far from their group's centroid to allow confident identifications (Table 4; Figure 3). The large Mahalanobis distances that mark many of the specimens suggest several possibilities: 1) The Thousand Creek assemblage contains the same genera, but different species (named or new) than the training set, 2) Thousand Creek samples the same species as the training set, but the unknown astragali reflect local adaptation to geographic and temporal variation in environment, 3) Sexual dimorphism within either dataset produces extra variance in shape and/or size that obscures taxonomic differences, 4) We may be sampling new genera, either undescribed or previously unknown from this interval, though this possibility is unlikely given the distribution of unknowns (Figure 2). Unfortunately, DFA could not diagnose new taxa that were not included in the training set if the last explanation were true.

Sexual dimorphism of large enough magnitude to obscure intergeneric differences is extremely unlikely, given that even marked sexual dimorphism is rarely large enough to mask species-level variation. For example, Davis and Calède (2012) were able to use the astragalus data from DeGusta and Vrba (2003) to successfully discriminate (100\% success) amongst species of Redunca, a highly sexually dimorphic genus of bovid antelope (Nowak and Paradiso, 1999). Another genus with strong sexual dimorphism, Tragelaphus, was less successfully discriminated, but still showed a remarkably high success rate of
45 out of 51 (88.24\%). The sexual dimorphism within the overall antelope dataset was not enough to disrupt species-level discrimination with $82.11 \%$ success, so we are not concerned that intraspecific sexual dimorphism is shaping our results. Time averaging in our paleontological data is a more likely source of variability at our study scale than sexual dimorphism.

In the training dataset, the three species of the Hemiauchenia-Pleiolama group are not significantly different in size or shape alone according to the Tukey test of PC1, but they are multivariately distinct enough for the DFA to correctly assign $79 \%$ of them (Table 3; Table 4). The relative size-similarity among the three species creates the apparent conflict between the Tukey tests and the DFA. The size differences among the seven taxa in the overall analysis are so great that the slight differences among the three species of Hemiauchenia-Pleiolama are lost in the Tukey test of PC1, which uses a pooled variance from the whole sample as part of its accounting for multiple comparisons. The DFA works from the individual group variances and includes all aspects of the multivariate dataset, not just size-related variance as with PC1. Consequently, the DFA can account for the subtler, shape-related differences between these group means (Figure 3). The differences among the astragali are slight enough that future studies aimed at diagnosing the occurrence of species (as opposed to genera) should depend upon the integration of results across several skeletal elements.

Many of the Thousand Creek specimens assigned to either Hemiauchenia edensis or "H." minima by the DFA have relatively high predictions for the other Hemiauchenia species and Pleiolama vera (Table 6). Similarly, the $P$. vera-identified specimens have secondary predictions for " $\mathrm{H}$." minima, but these secondary predictions are not as strong. In light of the lack of significant differences in astra- 
TABLE 3. Tukey HSD results for first three PC axes. Taxa not connected by the same letter are significantly different.

\begin{tabular}{|c|c|c|c|c|c|c|c|c|c|c|}
\hline Taxon & & & PC1 & & & & & & PC3 & \\
\hline Aepycamelus major & $A$ & & & & & A & & A & $B$ & \\
\hline Alforjas & & B & & & & & B & A & & $\mathrm{C}$ \\
\hline Megatylopus & & & C & & & A & B & & B & \\
\hline Procamelus & & & & $\mathrm{D}$ & & $A$ & B & & & C \\
\hline Pleiolama vera & & & & & $E$ & $A$ & & A & B & \\
\hline "Hemiauchenia" minima & & & & & E & A & & A & B & \\
\hline Hemiauchenia edensis & & & & & $\mathrm{E}$ & A & B & A & B & C \\
\hline
\end{tabular}

TABLE 4. Discriminant function analysis results for training set. Known identity in rows, predicted identity in columns. Correct identifications are in bold, with the number correct followed by the percent correct in parentheses. Incorrect identifications are in blue. The last row represents Mahalanobis distance cutoffs for predictions on unknowns.

\begin{tabular}{|c|c|c|c|c|c|c|c|c|}
\hline Full dataset & $\begin{array}{c}\text { Aepycamelus } \\
\text { major }\end{array}$ & Alforjas & Megatylopus & Procamelus & Pleiolama vera & $\begin{array}{c}\text { "Hemiauchenia" } \\
\text { minima }\end{array}$ & H. edensis & Totals \\
\hline Aepycamelus major & 44 (92\%) & & 4 & & & & & 48 \\
\hline Alforjas & & 22 (92\%) & & & 1 & 1 & & 24 \\
\hline Megatylopus & 1 & & 22 (96\%) & & & & & 23 \\
\hline Procamelus & & & & 6 (100\%) & & & & 6 \\
\hline Pleiolama vera & & & & & $8(89 \%)$ & & 1 & 9 \\
\hline $\begin{array}{l}\text { "Hemiauchenia" } \\
\text { minima }\end{array}$ & & & & & 5 & $52(79 \%)$ & & 66 \\
\hline $\begin{array}{l}\text { Hemiauchenia } \\
\text { edensis }\end{array}$ & & & & & 1 & 1 & $3(60 \%)$ & 5 \\
\hline Mahalanobis cutoff & 15.10 & 6.72 & 10.78 & 11.02 & 2.54 & 4.86 & 3.20 & \\
\hline Genus level & Aepycamelus & Alforjas & Megatylopus & Procamelus & Pleiolama & "Hemiauchenia" & Totals & \\
\hline Aepycamelus & 44 (92\%) & & 4 & & & & 48 & \\
\hline Alforjas & & 22 (92\%) & & & 1 & 1 & 24 & \\
\hline Megatylopus & 2 & & $21(88 \%)$ & & & & 23 & \\
\hline Procamelus & & & & $6(100 \%)$ & & & 6 & \\
\hline Pleiolama & & & & & $8(89 \%)$ & 1 & 9 & \\
\hline Hemiauchenia & & & & & 7 & $64(90 \%)$ & 71 & \\
\hline Mahalanobis cutoff & 15.12 & 6.68 & 10.80 & 11.08 & 2.56 & 5.46 & & \\
\hline $\begin{array}{l}\text { Lumped } \\
\text { "Hemiauchenia" }\end{array}$ & Aepycamelus & Alforjas & Megatylopus & Procamelus & "Hemiauchenia" & Totals & & \\
\hline Aepycamelus & $44(92 \%)$ & & 4 & & & 48 & & \\
\hline Alforjas & & $23(96 \%)$ & & & 1 & 24 & & \\
\hline Megatylopus & 1 & & $22(96)$ & & & 23 & & \\
\hline Procamelus & & & & $6(100 \%)$ & & 6 & & \\
\hline Hemiauchenia & & & & & 80 (100\%) & 80 & & \\
\hline Mahalanobis cutoff & 15.08 & 6.64 & 10.76 & 11.12 & 5.18 & & & \\
\hline
\end{tabular}




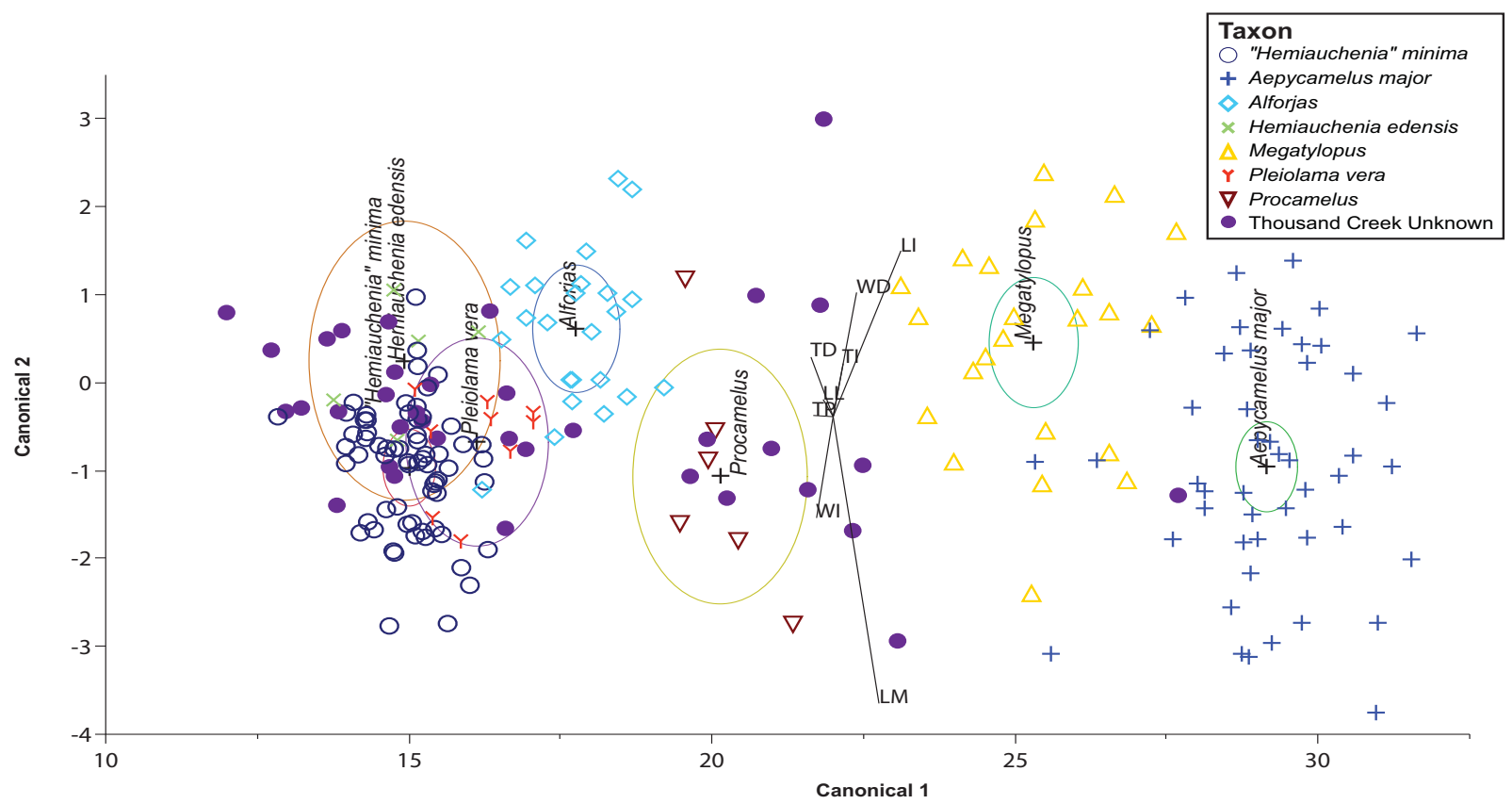

FIGURE 3. First two discriminant axes from species-level analysis. Camel taxa from the training set are indicated by the same shapes and colors as Figure 2. Ellipses show the 95\% confidence interval of the true mean.

galar morphology amongst these species, we assign all of the Thousand Creek astragali in this size class to "Hemiauchenia" sp., with the understanding that this grouping potentially includes Pleiolama. Increasing the sample size of known Pleiolama and Hemiauchenia astragali may also improve the ability of the discriminant function to distinguish between these groups.

The DFA clearly identifies at least three size classes of camels: "Hemiauchenia", Alforjas, and Procamelus (Table 4). The largest specimens in Thousand Creek are rejected from both Megatylopus and Aepycamelus by Mahalanobis distances, but are clearly large enough to deserve their own group. We identify these specimens as ?Megatylopus and suggest this large camelid may be a new or unsampled species of Megatylopus because of its relatively smaller Mahalanobis distance to that group's centroid as compared to Aepycamelus.

With at least four genera, Thousand Creek has a relatively high richness of camels, more than 97.1\% of Hemphillian sites containing camels in the western USA (data from MIOMAP; Carrasco et al., 2005). Combined with the number of equid, rhinocerotid, antilocaprid, and other large mammal species present, Thousand Creek may have had a rich consumer ecology, comparable to that of some areas of Africa today (McNaughton and Georgiadis, 1986). Taphonomy of the formation (i.e., a lakeshore environment and significant carnivore modification of bones) suggests that bone transport and aggregation of animals at water resources both contribute to the diversity of camelid remains. Time-averaging may also affect the apparent diversity at Thousand Creek; unfortunately, current geological study of the area does not place a strong constraint on sampling interval.

The camel diversity of Thousand Creek was previously unknown, with most references citing only Camelidae indet. Many camels from other mammal faunas from the Tertiary of North America have similarly been known simply as Camelidae indet., including over 260 localities in the MIOMAP database (Carrasco et al., 2005), e.g., sites within Cajon Valley (Woodburne and Golz, 1972), Kreb's Ranch (Shotwell, 1958), McKay Reservoir (Shotwell, 1956; Honey et al., 1998), Rattlesnake (Merriam et al., 1925), Thomas Farm (Pratt, 1990), Virgin Valley (Merriam, 1911), and Wolf Creek (Green, 1956). The possibility that these faunas might also include hidden camel diversity cannot be ignored.

Despite the improvement in our understanding of camelid diversity at Thousand Creek, the potential for paleoecological interpretations is limited. Quantitative assignment of habitat preference using DFA does not cross taxonomic groups well, as illustrated by the failure of a bovid habitat DFA 
TABLE 5. As for Table 4, but reflecting leave-one-out jackknife verification.

\begin{tabular}{|c|c|c|c|c|c|c|c|c|}
\hline Full dataset & $\begin{array}{c}\text { Aepycamelus } \\
\text { major }\end{array}$ & Alforjas & Megatylopus & Procamelus & Pleiolama vera & $\begin{array}{c}\text { "Hemiauchenia" } \\
\text { minima }\end{array}$ & H. edensis & Totals \\
\hline Aepycamelus major & $44(92 \%)$ & & 4 & & & & & 48 \\
\hline Alforjas & & $22(92 \%)$ & & & 1 & 1 & & 24 \\
\hline Megatylopus & 2 & & $21(91 \%)$ & & & & & 23 \\
\hline Procamelus & & & & $6(100 \%)$ & & & & 6 \\
\hline Pleiolama vera & & & & & 8 (89\%) & & 1 & 9 \\
\hline $\begin{array}{l}\text { "Hemiauchenia" } \\
\text { minima }\end{array}$ & & & & & 5 & $52(79 \%)$ & 9 & 66 \\
\hline $\begin{array}{l}\text { Hemiauchenia } \\
\text { edensis }\end{array}$ & & & & & 1 & 3 & $1(20 \%)$ & 5 \\
\hline Genus level & Aepycamelus & Alforjas & Megatylopus & Procamelus & Pleiolama & "Hemiauchenia" & Totals & \\
\hline Aepycamelus & 44 (92\%) & & 4 & & & & 48 & \\
\hline Alforjas & & $22(92 \%)$ & & & 1 & 1 & 24 & \\
\hline Megatylopus & 2 & & $21(91 \%)$ & & & & 23 & \\
\hline Procamelus & & & & $6(100 \%)$ & & & 6 & \\
\hline Pleiolama & & & & & $8(89 \%)$ & 1 & 9 & \\
\hline "Hemiauchenia" & & & & & 9 & $62(87 \%)$ & 71 & \\
\hline $\begin{array}{c}\text { Lumped } \\
\text { "Hemiauchenia" }\end{array}$ & Aepycamelus & Alforjas & Megatylopus & Procamelus & "Hemiauchenia" & Totals & & \\
\hline Aepycamelus & $44(92 \%)$ & & 4 & & & 48 & & \\
\hline Alforjas & & $23(96 \%)$ & & & 1 & 24 & & \\
\hline Megatylopus & 2 & & 21 (91\%) & & & 23 & & \\
\hline Procamelus & & & & $6(100 \%)$ & & 6 & & \\
\hline "Hemiauchenia" & & 1 & & & 79 (99\%) & 80 & & \\
\hline
\end{tabular}

to handle habitat preference in antilocaprids (Davis and Calède, 2012). In the absence of an existing paleoenvironmental DFA for camelids, the production of which would be difficult given the limited number of extant species, we cannot comment on the Thousand Creek habitats using camelid astragali alone. Future studies with an approach similar to the Janis et al. (2002) investigation of locomotor evolution, with a focus on astragali rather than metapodials, may make ecomorphological interpretations possible.

Our approach has been one of repeatable statistical analysis, and as a consequence our conclusions cannot be as straightforward as a traditional qualitative analysis of similar data. The training set clearly shows size-related distinction between the included genera, but the boundaries of each taxonomic sample overlap. Size-independent shape differences are also important in distinguishing these taxa and cannot be clearly captured by qualitative analysis of the PCA biplot. Further, the Thou- sand Creek specimens cross several taxonomic groups from the training set (Figure 2), without clear borders. It would be difficult to justify assigning the specimens to these taxa in the absence of the quantitative results of the DFA (Table 6; Figure 3). A rigorous statistical approach allows us to 1 ) clearly express our precision in our identifications and 2) provide a beginning dataset for expansion through added training specimens so that future workers may increase the precision of their taxonomic analyses.

\section{CONCLUSIONS}

Our DFA contributes towards establishment of a standardized, quantitative method for the assignment of specimens to mammalian taxa at localities where diagnostic cranial and dental material are not present. Ideally, taxonomic assignments would be made on the basis of phylogenetic characters (Bell et al., 2010), but in cases where the majority of specimens are phylogenetically indeterminate, 
DFA can at least narrow the possible taxa present. Our ultimate goal is to make any fossil assemblage, no matter its particular taphonomic pathway, a contributor to large-scale studies of paleofaunal diversity, both richness and evenness (e.g., Alroy et al., 2000; Barnosky and Carrasco, 2002).

Using eight linear measurements of astragali (Figure 1) from the Hemphillian Thousand Creek fauna of Nevada, we have been able to identify four camelid taxa: "Hemiauchenia", Alforjas, Procamelus, and ?Megatylopus (Table 6). The "Hemiauchenia" specimens clearly belong to the species complex that includes members of both Hemiauchenia and Pleiolama. The ?Megatylopus specimens are in the same size-class as Megatylopus and Aepycamelus, but do not clearly cluster with the training sample of either of those genera. We are more confident in the assignment of specimens to Alforjas and Procamelus. No matter the true taxonomic identity of these specimens, we can substantiate the presence of four distinct size classes in the fauna, an important insight for paleoecological studies at the local and landscape level and a considerable improvement over the previous "Camelidae indet." For our analysis, we have used the "lumped" discriminant function; a genus-level analysis would also be appropriate for future identifications of other camelid astragali, provided the investigator were aware of the potential conflation of Pleiolama with Hemiauchenia. Adding new specimens to the training data might remove this ambiguity and could improve the success rates for the other taxa. Our training dataset can be applied to any camelid assemblages from the early Hemphillian, but a new training set will be needed for other time intervals.

\section{ACKNOWLEDGMENTS}

Thanks to P. Holroyd (UCMP), S. Bell $(\mathrm{AMNH}), \mathrm{R}$. Evander $(\mathrm{AMNH})$, and $\mathrm{D}$. Tedford (AMNH) for access to specimens. The UCMP collections used for this project come primarily from BLM land, and this scientific work would not be possible without BLM support. We thank members of the Barnosky Lab and Hopkins Lab for productive discussion. EBD is indebted to the George C. Louderback Fund, Inc. for financing his digital calipers and part of his trip to AMNH. BKM would like to thank K. and K. Singer, who have provided support for several years. Finally we thank the two anonymous reviewers whose feedback greatly improved this paper. Part of the trip to AMNH was funded by the Geological Society of America. Portions of this research were conducted while EBD was a Graduate Research Fellow of the National Science Foundation and others while BKM was a Goldwater Scholar. BKM was also funded by the Singer Foundation, University of Oregon, UO Department of Biology, and UO Robert D. Clark Honors College.

\section{REFERENCES}

Ach, J.A. and Swisher, C.C. 1990. The High Rock caldera complex; nested "failed" calderas in northwestern Nevada. Eos Transactions of the American Geophysical Union, 71:1614.

Alroy, J., Koch, P.L., and Zachos, J.C. 2000. Global climate change and North American mammalian evolution, p. 259-288. In Erwin, D.H. and Wing, S.L. (eds.), Deep Time: Paleobiology's Perspective. Allen Press, Kansas.

Barnosky, A.D. and Carrasco, M.A. 2002. Effects of Oligo-Miocene global climate changes on mammalian species richness in the northwestern quarter of the USA. Evolutionary Ecology Research, 4:811-841.

Behrensmeyer, A.K., Hook, R.W., Badgley, C.E., Boy, J.A., Chapman, R.E., Dodson, P., Gastaldo, R.A., Graham, R.W., Martin, L.D., Olsen, P.E., Spicer, R.A., Taggart, R.E., and Wilson, M.V.H. 1992. Paleoenvironmental contexts and taphonomic modes, p. 15136. In Behrensmeyer, A.K., DiMichele, W.A., Potts, R., and Sues, H.-D. (eds.), Terrestrial Ecosystems through Time: Evolutionary Paleoecology of Terrestrial Plants and Animals. University of Chicago Press, Chicago.

Bell, C.J., Gauthier, J.A., and Bever, G.S. 2010. Covert biases, circularity, and apomorphies: a critical look at the North American Quaternary Herpetofaunal Stability Hypothesis. Quaternary International, 217:30-36.

Breyer, J.A. 1983. The biostratigraphic utility of camel metapodials. Journal of Paleontology, 57:302-307.

Carrasco, M.A., Kraatz, B.P., Davis, E.B., and Barnosky, A.D. 2005. Miocene Mammal Mapping Project (MIOMAP). University of California Museum of Paleontology. http://www.ucmp.berkeley.edu/miomap/

Davis, E.B. and Calède, J.J.M. 2012. Extending the utility of artiodactyl postcrania for species-level identifications using multivariate morphometric analyses. Palaeontologia Electronica 15.1.1A: 22pp, 2.09MB; http://palaeo-electronica.org/content/2012-issue-1articles/68-artiodactyl-postcrania.

Davis, E.B. and Pyenson, N.D. 2007. Diversity biases in terrestrial mammalian assemblages and quantifying the differences between museum collections and published accounts: a case study from the Miocene of Nevada. Palaeogeography Palaeoclimatology Palaeoecology, 250:139-149.

DeGusta, D. and Vrba, E.S. 2003. A method for inferring paleohabitats from the functional morphology of bovid astragali. Journal of Archaeological Science, 30:1009-1022. 
DeGusta, D. and Vrba, E.S. 2005. Methods for inferring paleohabitats from the functional morphology of bovid phalanges. Journal of Archaeological Science, 32: 1099-1113.

Frick, C. 1921. Extinct vertebrate faunas of the Badlands of Bautista Creek and San Timoteo Canyon, southern California. California University Department of Geology Bulletin, 12:277-424.

Fyock, T.L. 1963. The stratigraphy and structure of the Virgin Valley-Thousand Creek area. Unpublished MS Thesis, University of Washington, Seattle, Washington, USA.

Green, M. 1956. The lower Pliocene Ogallala-Wolf Creek vertebrate fauna, South Dakota. Journal of Paleontology, 30:146-169.

Green, R.C. 1984. Geologic appraisal of the Charles Sheldon Wilderness Study Area, Nevada and Oregon. United States Geological Survey Bulletin, 1538:13-34

Hammer, Ø. and Harper, D. 2006. Paleontological Data Analysis. Blackwell Publishing, Oxford.

Honey, J.G., Harrison, J.A., Prothero, D.R., and Stevens, M.S. 1998. Camelidae, p. 439-462. In Janis, C.M., Scott, K.M., and Jacobs, L.L. (eds.), Evolution of Tertiary Mammals of North America. Cambridge University Press, New York.

Hopkins, S.S.B. and Davis, E.B. 2009. Quantitative morphological proxies for fossoriality in small mammals. Journal of Mammalogy, 90:1449-1460.

Hurvich, C.M. and Tsai, C.L. 1989. Regression and time series model selection in small samples. Biometrika, 76:297-307.

Janis, C.M., Theodor, J.M., and Boisvert, B. 2002. Locomotor evolution in camels revisited: a quantitative analysis of pedal anatomy and the acquisition of the pacing gait. Journal of Vertebrate Paleontology, 22:110-121.

JMP Pro, Version 9.0. SAS Institute Inc., Cary, NC, 1989-2012.

Klein, R.G., Fanciscus, R.G., and Steele, T.E. 2010. Morphometric identification of bovid metapodials to genus and implications for taxon-free habitat reconstruction. Journal of Archaeological Science, 37:389401.

Kovarovic, K., Aiello, L.C., Cardini, A., and Lockwood, C.A. Discriminant function analyses in archaeology: are classification rates too good to be true? Journal of Archaeological Science, 38:3006-3018.

Leidy, P. 1887. Fossil bones from Florida. Proceedings of the Academy of Natural Sciences of Philadelphia, 39:309-310

Louys, J., Montanari, S., Plummer, T., Hertel, F., and Bishop, L.C. 2012. Evolutionary divergence and convergence in shape and size within African antelope proximal phalanges. Journal of Mammalian Evolution, 1-10.
Martinez, J.N. and Sudre, J. 1995. The astragalus of Paleogene artiodactyls: comparative morphology, variability and prediction of body mass. Lethaia, 28:197-209.

McGuire, J.L. 2011. Identifying California Microtus species using geometric morphometrics documents Quaternary geographic range contractions. Journal of Mammalogy, 92:1383-1394.

McNaughton, S.J. and Georgiadis, N.J. 1986. Ecology of African grazing and browsing mammals. Annual Review of Ecology and Systematics, 17:39-65.

Meloro, C. 2011. Feeding habits of Plio-Pleistocene large carnivores as revealed by their mandibular geometry. Journal of Vertebrate Paleontology 31:428-446

Meloro, C., Elton, S., Louys, J., Bishop, L.C., and Ditchfield, P. 2013. Cats in the forest: predicting habitat adaptations from humerus morphometry in extant and fossil Felidae (Carnivora). Paleobiology 39:323344.

Merriam, J.C. 1910. Tertiary mammal beds of Virgin Valley and Thousand Creek in northwestern Nevada, Part I: geologic history. University of California Publications, Bulletin of the Department of Geology, 6:2153.

Merriam, J.C. 1911, Tertiary mammal beds of Virgin Valley and Thousand Creek in northwestern Nevada, Part II - Vertebrate faunas. University of California Publications in Geological Sciences, 6:199-304.

Merriam, J.C., Stock, C., and Moody, C.L., 1925. The Pliocene Rattlesnake Formation and fauna of eastern Oregon with notes on the geology of the Rattlesnake and Mascall deposits. Contributions to Paleontology, Carnegie Institution of Washington, 347:43-92.

Nowak, R.M. and Paradiso, J.L. 1999. Walker's Mammals of the World. Johns Hopkins University Press, Baltimore, Maryland.

Perkins, M.E., Brown, F.H., Nash, W.P., Mclntosh, W., and Williams, S.K. 1998. Sequence, age, and source of silicic fallout tuffs in middle to late Miocene basins of the northern Basin and Range province. Geological Society of America Bulletin, 110:344-360.

Pratt, A.E. 1990. Taphonomy of the large vertebrate fauna from the Thomas Farm locality (Miocene, Hemingfordian), Gilchrist County, Florida. Bulletin of the Florida Museum of Natural History, 35:35-130.

Prothero, D.R. 2005. The Evolution of North American Rhinoceroses. Cambridge University Press.

Prothero, D.R. and Davis, E.B. 2008. Magnetic stratigraphy of the upper Miocene (early Hemphillian) Thousand Creek Formation, northwestern Nevada. New Mexico Museum of Natural History and Science Bulletin, 44:233-237.

R Core Team. 2012. R: A language and environment for statistical computing. R Foundation for Statistical Computing, Vienna, Austria. ISBN 3-900051-07-0, http://www.R-project.org/. 
Schaeffer, B. 1947. Notes on the origin and function of the artiodactyl tarsus. American Museum Novitates, 1356:1-24.

Shotwell, J.A. 1956. Hemphillian mammalian assemblage from northeastern Oregon. Bulletin of the Geological Society of America, 67:717-738.

Shotwell, J.A. 1958. Inter-community relationships in Hemphillian (mid-Pliocene) mammals. Ecology, 39:271-282.

Spaulding, M. and Flynn, J.J. 2012. Phylogeny of the Carnivoramorpha: the impact of postcranial characters. Journal of Systematic Palaeontology, 10:653677.

Streck, M.J. and Grunder, A.L. 1995. Crystallization and welding variations in a widespread ignimbrite sheet; the Rattlesnake Tuff, eastern Oregon, USA. Bulletin of Volcanology, 57:151-169.

Swisher, C.C. III. 1992. 40Ar/39Ar dating and its application to the calibration of the North American landmammal ages. Unpublished PhD Dissertation, University of California, Berkeley, California, USA.

van Asperen, E.N. 2011. Distinguishing between the late Middle Pleistocene interglacials of the British Isles: A multivariate approach to horse biostratigraphy. Quaternary International, 231:110-115.
Venables, W.N. and Ripley, B.D. 2002. Modern Applied Statistics with S, Fourth Edition. Springer.

Webb, S.D., Hulbert, R.C., Morgan, G.S., and Evans, H.E. 2008. Terrestrial mammals of the Palmetto Fauna (early Pliocene, latest Hemphillian) from the central Florida phosphate district. Natural History Museum Los Angeles County Science Series, 41:293-312.

Webb, S.D. and Meachen, J. 2004. On the origin of lamine Camelidae including a new genus from the Late Miocene of the High Plains. Bulletin of Carnegie Museum of Natural History, 36:349-362.

Webb, S.D., MacFadden, B.J., and Baskin, J.A. 1981. Geology and paleontology of the Love Bone Bed from the late Miocene of Florida. American Journal of Science, 281:513-544.

Wendell, W.G. 1970. The structure and stratigraphy of the Virgin Valley-McGee Mountain area, Humboldt County, Nevada. Unpublished MS Thesis, Oregon State University, Corvallis, Oregon, USA.

Woodburne, M.O. and Golz, D.J. 1972. Stratigraphy of the Punchbowl Formation, Cajon Valley, southern California. University of California Publications in Geological Sciences, 92:1-73. 
TABLE 6. Taxonomic assignments of Thousand Creek unknown camel astragali from each of the three discriminant analyses, accompanied by probability $(p)$ and Mahalanobis Distance. Bold name indicates acceptable identification, while a blue name indicates a rejected identification on the basis of probability $(<0.5)$ or Mahalanobis distance too great. Probabilities and distances are similarly bold or blue to indicate acceptance or rejection. The secondary predictions are listed for each analysis, along with their probabilities and distances; no second prediction is listed if all had $\mathrm{p}<0.01$.

\begin{tabular}{|c|c|c|c|c|c|c|c|c|c|c|c|c|c|}
\hline \multirow[b]{2}{*}{ Loc. No } & \multirow[b]{2}{*}{$\begin{array}{c}\text { Spec. } \\
\text { No. }\end{array}$} & \multicolumn{6}{|c|}{ Full Dataset } & \multicolumn{6}{|c|}{ Genus level } \\
\hline & & Prediction & $\mathbf{p}$ & Dist & 2nd. Pred. & $\mathbf{p}$ & Dist & Prediction & p & Dist & 2nd & $\mathbf{p}$ & Dist. \\
\hline 2744 & 70461 & A. major & 0.95 & 30.6 & Megatylopus & 0.05 & 36.4 & Aepycamelus & 0.94 & 30.7 & Megatylopus & 0.06 & 36.3 \\
\hline V6570 & 164715 & Alforjas & 0.63 & 20.3 & Procamelus & 0.35 & 21.5 & Alforjas & 0.63 & 20.3 & Procamelus & 0.34 & 21.6 \\
\hline 2744 & 70463 & Alforjas & 0.75 & 6.7 & Procamelus & 0.14 & 10.1 & Alforjas & 0.77 & 6.6 & Procamelus & 0.13 & 10.2 \\
\hline 2744 & 164708 & Alforjas & 0.94 & 12.6 & Procamelus & 0.05 & 18.4 & Alforjas & 0.94 & 12.7 & Procamelus & 0.06 & 18.1 \\
\hline 2744 & 164707 & Megatylopus & 0.50 & 12.4 & Procamelus & 0.50 & 12.4 & Megatylopus & 0.52 & 12.3 & Procamelus & 0.48 & 12.5 \\
\hline V78053 & 164712 & Megatylopus & 0.88 & 27.4 & Procamelus & 0.08 & 32.3 & Megatylopus & 0.86 & 27.0 & Procamelus & 0.11 & 31.2 \\
\hline V99410 & 158359 & Megatylopus & 1.00 & 31.6 & & & & Megatylopus & 1.00 & 31.7 & & & \\
\hline V6570 & 31379 & Procamelus & 0.76 & 19.7 & Alforjas & 0.23 & 22.0 & Procamelus & 0.74 & 19.8 & Megatylopus & 0.01 & 28.9 \\
\hline 2744 & 164709 & Procamelus & 0.94 & 14.2 & Megatylopus & 0.06 & 19.7 & Procamelus & 0.94 & 14.3 & Megatylopus & 0.06 & 19.7 \\
\hline 1101 & 70346 & Procamelus & 0.94 & 19.8 & Megatylopus & 0.05 & 25.5 & Procamelus & 0.95 & 19.7 & Megatylopus & 0.05 & 25.6 \\
\hline 2744 & 164728 & Procamelus & 0.96 & 7.9 & Alforjas & 0.04 & 14.1 & Procamelus & 0.95 & 7.9 & Alforjas & 0.05 & 14.0 \\
\hline V78050 & 164713 & Procamelus & 0.98 & 29.6 & Megatylopus & 0.01 & 38.3 & Procamelus & 0.98 & 29.7 & Megatylopus & 0.01 & 38.5 \\
\hline V99448 & 157285 & Procamelus & 0.99 & 6.1 & & & & Procamelus & 0.99 & 6.1 & & & \\
\hline 2744 & 164725 & $P$. vera & 0.32 & 13.3 & Alforjas & 0.30 & 13.4 & Pleiolama & 0.36 & 13.4 & Alforjas & 0.35 & 13.4 \\
\hline 2739 & 164726 & $P$. vera & 0.47 & 13.5 & H. edensis & 0.38 & 13.9 & Pleiolama & 0.74 & 13.5 & "Hemiauchenia" & 0.26 & 15.6 \\
\hline 2744 & 70464 & P. vera & 0.49 & 13.7 & "H." minima & 0.33 & 14.5 & Pleiolama & 0.53 & 13.7 & "Hemiauchenia" & 0.32 & 14.7 \\
\hline V91097 & 164774 & P. vera & 0.51 & 3.7 & Alforjas & 0.23 & 5.3 & Pleiolama & 0.57 & 3.7 & Alforjas & 0.26 & 5.3 \\
\hline V99410 & 158358 & P. vera & 0.72 & 6.6 & "H." minima & 0.16 & 9.6 & Pleiolama & 0.77 & 6.6 & "Hemiauchenia" & 0.17 & 9.6 \\
\hline V69107 & 164714 & "H." minima & 0.45 & 11.6 & H. edensis & 0.35 & 12.1 & "Hemiauchenia" & 0.70 & 11.5 & Pleiolama & 0.30 & 13.2 \\
\hline V78061 & 164716 & "H." minima & 0.46 & 4.4 & H. edensis & 0.44 & 4.6 & "Hemiauchenia" & 0.83 & 4.3 & Pleiolama & 0.15 & 7.8 \\
\hline 1100 & 35633 & "H." minima & 0.48 & 3.2 & H. edensis & 0.42 & 3.5 & "Hemiauchenia" & 0.84 & 3.1 & Pleiolama & 0.15 & 6.5 \\
\hline V69106 & 164720 & "H." minima & 0.54 & 4.7 & H. edensis & 0.43 & 5.2 & "Hemiauchenia" & 0.96 & 4.6 & Pleiolama & 0.04 & 11.2 \\
\hline V6570 & 164727 & "H." minima & 0.55 & 2.0 & H. edensis & 0.27 & 3.5 & "Hemiauchenia" & 0.76 & 2.0 & Pleiolama & 0.24 & 4.3 \\
\hline V69106 & 164721 & "H." minima & 0.55 & 7.6 & H. edensis & 0.42 & 8.1 & "Hemiauchenia" & 0.96 & 7.5 & Pleiolama & 0.04 & 14.0 \\
\hline V99414 & 158399 & "H." minima & 0.58 & 2.6 & H. edensis & 0.34 & 3.7 & "Hemiauchenia" & 0.88 & 2.5 & Pleiolama & 0.12 & 6.5 \\
\hline V99448 & 157286 & "H." minima & 0.70 & 2.2 & H. edensis & 0.15 & 5.3 & "Hemiauchenia" & 0.81 & 2.3 & Pleiolama & 0.16 & 5.6 \\
\hline 2744 & 164724 & "H." minima & 0.70 & 3.2 & H. edensis & 0.21 & 5.6 & "Hemiauchenia" & 0.88 & 3.2 & Pleiolama & 0.09 & 7.8 \\
\hline V69106 & 164723 & "H." minima & 0.81 & 4.4 & H. edensis & 0.14 & 7.9 & "Hemiauchenia" & 0.94 & 4.5 & Pleiolama & 0.06 & 10.0 \\
\hline V78075 & 164755 & H. edensis & 0.37 & 7.2 & "H." minima & 0.34 & 7.4 & "Hemiauchenia" & 0.56 & 7.3 & Pleiolama & 0.44 & 7.7 \\
\hline V69114 & 164718 & H. edensis & 0.37 & 15.2 & "H." minima & 0.16 & 16.9 & Alforjas & 0.54 & 15.3 & "Hemiauchenia" & 0.28 & 16.6 \\
\hline V69106 & 84648 & H. edensis & 0.51 & 13.8 & "H." minima & 0.35 & 14.5 & "Hemiauchenia" & 0.74 & 14.3 & Pleiolama & 0.26 & 16.4 \\
\hline V99414 & 157206 & H. edensis & 0.56 & 9.8 & "H." minima & 0.30 & 11.1 & "Hemiauchenia" & 0.71 & 10.8 & Pleiolama & 0.29 & 12.7 \\
\hline V99451 & 153817 & H. edensis & 0.57 & 7.8 & "H." minima & 0.42 & 8.4 & "Hemiauchenia" & 0.97 & 8.2 & Pleiolama & 0.03 & 15.3 \\
\hline V69106 & 164719 & H. edensis & 0.72 & 6.6 & "H." minima & 0.17 & 9.5 & "Hemiauchenia" & 0.64 & 9.1 & Pleiolama & 0.36 & 10.3 \\
\hline 2741 & 70417 & H. edensis & 0.75 & 14.2 & "H." minima & 0.24 & 16.5 & "Hemiauchenia" & 0.98 & 16.2 & Pleiolama & 0.02 & 23.5 \\
\hline 2739 & 70390 & H. edensis & 0.79 & 16.7 & "H." minima & 0.19 & 19.6 & "Hemiauchenia" & 0.91 & 19.2 & Pleiolama & 0.07 & 24.2 \\
\hline
\end{tabular}


TABLE 6 continued.

\begin{tabular}{|c|c|c|c|c|c|c|c|}
\hline \multirow[b]{2}{*}{ Loc. No } & \multirow[b]{2}{*}{$\begin{array}{c}\text { Spec. } \\
\text { No. }\end{array}$} & \multicolumn{6}{|c|}{ Lumped "Hemiauchenia" } \\
\hline & & Prediction & $\mathbf{p}$ & Dist. & 2nd & $\mathbf{p}$ & Dist \\
\hline 2744 & 70461 & Aepycamelus & 0.96 & 30.3 & Megatylopus & 0.04 & 36.5 \\
\hline V6570 & 164715 & Alforjas & 0.69 & 19.8 & Procamelus & 0.31 & 21.4 \\
\hline 2744 & 70463 & Alforjas & 0.80 & 6.7 & Procamelus & 0.14 & 10.1 \\
\hline 2744 & 164708 & Alforjas & 0.94 & 12.3 & Procamelus & 0.05 & 18.1 \\
\hline 2744 & 164707 & Procamelus & 0.50 & 11.7 & Megatylopus & 0.50 & 11.7 \\
\hline V78053 & 164712 & Megatylopus & 0.75 & 27.0 & Procamelus & 0.17 & 29.9 \\
\hline V99410 & 158359 & Megatylopus & 1.00 & 31.8 & & & \\
\hline V6570 & 31379 & Procamelus & 0.71 & 19.7 & Alforjas & 0.28 & 21.6 \\
\hline 2744 & 164709 & Procamelus & 0.96 & 13.1 & Megatylopus & 0.04 & 19.4 \\
\hline 1101 & 70346 & Procamelus & 0.91 & 19.6 & Megatylopus & 0.09 & 24.3 \\
\hline 2744 & 164728 & Procamelus & 0.95 & 8.0 & Alforjas & 0.05 & 14.0 \\
\hline V78050 & 164713 & Procamelus & 0.96 & 29.7 & Megatylopus & 0.03 & 36.8 \\
\hline V99448 & 157285 & Procamelus & 0.99 & 6.1 & Alforjas & 0.01 & 16.0 \\
\hline 2744 & 164725 & "Hemiauchenia" & 0.50 & 13.4 & Alforjas & 0.49 & 13.5 \\
\hline 2739 & 164726 & "Hemiauchenia" & 0.98 & 14.9 & Alforjas & 0.02 & 23.2 \\
\hline 2744 & 70464 & "Hemiauchenia" & 0.75 & 14.2 & Alforjas & 0.24 & 16.4 \\
\hline V91097 & 164774 & Alforjas & 0.50 & 5.3 & "Hemiauchenia" & 0.50 & 5.3 \\
\hline V99410 & 158358 & "Hemiauchenia" & 0.82 & 8.7 & Alforjas & 0.18 & 11.7 \\
\hline V69107 & 164714 & "Hemiauchenia" & 1.00 & 11.4 & & & \\
\hline V78061 & 164716 & "Hemiauchenia" & 0.98 & 4.4 & Alforjas & 0.02 & 11.8 \\
\hline 1100 & 35633 & "Hemiauchenia" & 0.99 & 3.2 & & & \\
\hline V69106 & 164720 & "Hemiauchenia" & 1.00 & 4.9 & & & \\
\hline V6570 & 164727 & "Hemiauchenia" & 1.00 & 1.9 & & & \\
\hline V69106 & 164721 & "Hemiauchenia" & 1.00 & 7.8 & & & \\
\hline V99414 & 158399 & "Hemiauchenia" & 0.99 & 2.7 & & & \\
\hline V99448 & 157286 & "Hemiauchenia" & 0.96 & 2.4 & Alforjas & 0.04 & 8.6 \\
\hline 2744 & 164724 & "Hemiauchenia" & 0.96 & 3.4 & Alforjas & 0.04 & 10.0 \\
\hline V69106 & 164723 & "Hemiauchenia" & 1.00 & 4.7 & & & \\
\hline V78075 & 164755 & "Hemiauchenia" & 0.99 & 7.0 & & & \\
\hline V69114 & 164718 & Alforjas & 0.64 & 15.3 & "Hemiauchenia" & 0.36 & 16.5 \\
\hline V69106 & 84648 & "Hemiauchenia" & 1.00 & 14.3 & & & \\
\hline V99414 & 157206 & "Hemiauchenia" & 1.00 & 10.8 & & & \\
\hline V99451 & 153817 & "Hemiauchenia" & 1.00 & 8.5 & & & \\
\hline V69106 & 164719 & "Hemiauchenia" & 1.00 & 8.9 & & & \\
\hline 2741 & 70417 & "Hemiauchenia" & 1.00 & 16.5 & & & \\
\hline 2739 & 70390 & "Hemiauchenia" & 0.97 & 19.5 & Alforjas & 0.03 & 26.8 \\
\hline
\end{tabular}

